\title{
The effect of four interventions on the informational content of histopathology reports of resected colorectal carcinomas
}

\author{
Simon S Cross, Kenneth M Feeley, Carole A Angel
}

Department of Pathology, University of Sheffield Medical School, Sheffield, UK S S Cross K M Feeley

C A Angel

Correspondence to: Dr S S Cross, Department of Pathology, University of Sheffield Medical School, Beech Hill Road, Sheffield S10 2RX, UK;

email: s.s.cross@ sheffield.ac.uk

Accepted for publication 24 March 1998

\begin{abstract}
Aim-To investigate the effect of different interventions on the inclusion of data items in the histopathology reports of resected colorectal carcinomas.

Study population-272 routine histopathology reports on colorectal carcinomas from the department of histopathology, Royal Hallamshire Hospital, Sheffield. Methods-The presence or absence of 10 specific data items was recorded for each report. The reports were divided into five audit periods. In the initial period reports were generated using free text with no agreed guidelines. In period 2 , text guidelines had been issued; in period 3, flow diagram guidelines had been issued; and
\end{abstract}

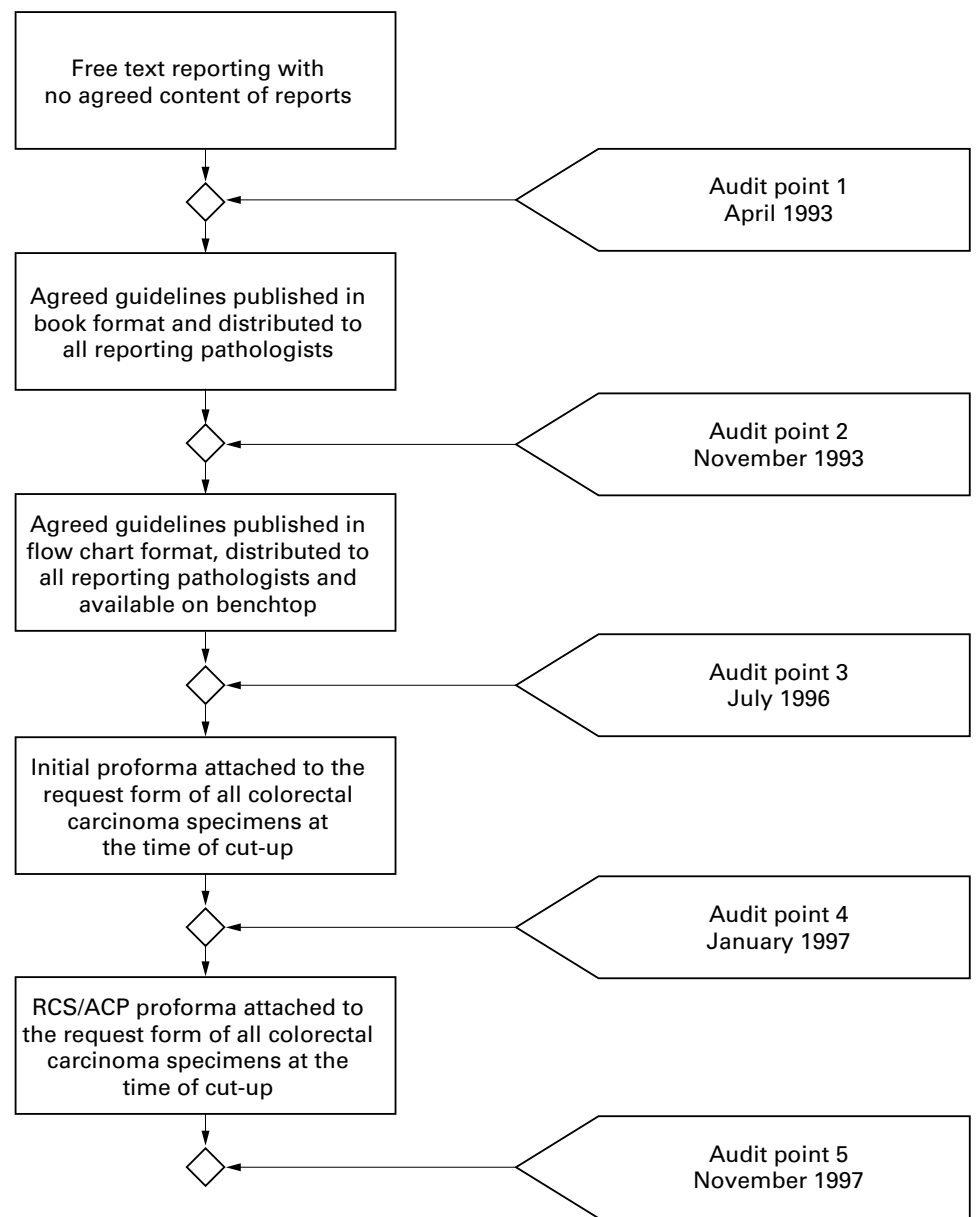

Figure 1 Flow diagram showing the audit points and described interventions during the study. in periods 4 and 5 , template proformas were attached to each specimen request form.

Results-All interventions produced some increase in inclusion rate for some features, but only with the introduction of template proformas did these rates approach $100 \%$ for all data items. Inclusion rates were $100 \%$ for all items in all cases reported using a proforma. In the final audit period $96 \%$ of specimens were reported using proformas.

Conclusions-Template proformas produce a high rate of inclusion of data items in reports of colorectal carcinoma resection specimens.

(F Clin Pathol 1998;51:481-482)

Keywords: colorectal cancer; histopathology audit; quality control

Recent publications have highlighted deficiencies in the informational content of many routine reports on colorectal cancer resection specimens. ${ }^{12}$ The information in these reports is vital for patient management, especially the status of the circumferential resection margin and lymph nodes, ${ }^{3}$ and if new technologies are to produce better estimates of prognosis then reliable and complete reporting of data items is required. ${ }^{4}$ Recent reports have suggested that template proformas could improve the rate of inclusion of features in reports ${ }^{12}$ but we are not aware of any published studies to support this suggestion. In this study we audited the informational content of reports at a single hospital over four years with the introduction of four interventions, including template proformas, designed to improve the rate of feature inclusion.

\section{Methods}

The informational content of routine histopathology reports on colorectal cancer resection specimens in the department of histopathology, Royal Hallamshire Hospital, Sheffield, was audited at five points between April 1993 and November 1997. Consecutive reports from the period immediately preceding each audit point were examined and the presence or absence of specific data items was recorded by a histopathologist. Explicit statement of the data item was required, for example Dukes' stage was only recorded as present if explicitly stated although it could be deduced from the depth of invasion and lymph node status. The audit points and interventions are shown in fig 1 , and 
Table 1 The specific data items sought in each report and the percentage of reports which contained explicit statement of each item

\begin{tabular}{llllll}
\hline & April 1993 & November 1993 & fuly 1996 & fanuary 1997 & November 1997 \\
\hline Audit point & 1 & 2 & 3 & 4 & 5 \\
No of reports & 50 & 50 & 43 & 61 & 68 \\
Type & $100 \%$ & $100 \%$ & $100 \%$ & $100 \%$ & $100 \%$ \\
Grade & $98 \%$ & $98 \%$ & $100 \%$ & $100 \%$ & $100 \%$ \\
Depth of invasion & $\mathrm{n} / \mathrm{a}$ & $\mathrm{n} / \mathrm{a}$ & $100 \%$ & $100 \%$ & $100 \%$ \\
Vascular invasion & $\mathrm{n} / \mathrm{a}$ & $\mathrm{n} / \mathrm{a}$ & $88 \%$ & $97 \%$ & $100 \%$ \\
Circumferential resection margin & $31 \%$ & $68 \%$ & $86 \%$ & $97 \%$ & $100 \%$ \\
Other resection margins & $\mathrm{n} / \mathrm{a}$ & $\mathrm{n} / \mathrm{a}$ & $54 \%$ & $97 \%$ & $100 \%$ \\
Lymph node status & $98 \%$ & $98 \%$ & $100 \%$ & $100 \%$ & $100 \%$ \\
Background mucosa & $\mathrm{n} / \mathrm{a}$ & $\mathrm{n} / \mathrm{a}$ & $65 \%$ & $97 \%$ & $99 \%$ \\
Dukes' stage & $72 \%$ & $86 \%$ & $100 \%$ & $97 \%$ & $100 \%$ \\
TNM stage & $\mathrm{n} / \mathrm{a}$ & $\mathrm{n} / \mathrm{a}$ & $0 \%$ & $2 \%$ & $97 \%$ \\
Use of proforma & $0 \%$ & $0 \%$ & $0 \%$ & $84 \%$ & $96 \%$ \\
\hline
\end{tabular}

n/a, not available.

the specific data items and number of reports examined in each period are shown in the results (table 1). The initial proforma, audited at point 4 , was designed within the audited department. The second proforma, audited at point 5, was based on the Royal College of Surgeons/Association of Coloproctology (RCS/ACP) national guidelines minimum dataset. ${ }^{6}$ The reporting pathologists using proformas highlighted the statements that they wished to include in the report using a marker pen, and secretarial staff typed the reports from these. Pathologists were free to choose whether they used the proformas or other means of generating a report (most commonly dictation).

Results

The results are summarised in table 1 . At audit points 4 and 5 the cases which were not reported using a proforma $(16 \%$ and $4 \%$ respectively) were reported using dictation. In all cases where a proforma was used the inclusion rate was $100 \%$ for all data items.

\section{Discussion}

It can be seen that three items-tumour type, histological grade, and lymph node statuswere reported at a rate of almost $100 \%$ at the first audit, but other items, notably the circumferential resection margin, had a low rate of inclusion. The importance of reporting the status of the circumferential resection margin was first described in a widely distributed journal in $1986,{ }^{7}$ so the reporting pathologists should have been aware of this. The design and distribution of an internal set of guidelines for dissection and reporting (between audit points 1 and 2) produced a large increase in inclusion of some features (31\% to $68 \%$ for the circumferential resection margin) and distribution of the colorectal carcinoma guidelines in flow diagram format for use on the benchtop produced further increases. However, it was not until a template proforma was attached to the request form of every colorectal carcinoma resection specimen that the item inclusion rates approached $100 \%$ in all categories. Use of the proforma produced $100 \%$ inclusion of all data items but its presence also increased the inclusion rates in dictated reports to close to $100 \%$, probably by acting as an ever present aide mémoire. The use of the proforma increased to nearly $100 \%$ with the introduction of the RCS/ ACP minimum dataset proforma. This proforma has 11 more data items than our initial internally designed proforma ${ }^{6}$ and it probably represents the watershed at which reluctant users assess that it is quicker to use the proforma than to dictate the report (an informal study showed that it was quicker to use the proforma than to dictate a report even with the initial proforma).

These results suggest that an effective method of ensuring an adequate informational content of reports on colorectal carcinoma resection specimens is the use of template proformas, of which the Joint National Guidelines minimum dataset (virtually identical with the RCS/ACP minimum dataset used in this study) is becoming the definitive example in Britain and Europe. As the amount of information increases in all types of histopathology reports $^{8}$ the proforma system may find widespread application. Its use in reporting mastectomy specimens has already been described. ${ }^{9}$ Judicious use of newer information technology, such as electronic proformas with touch screen selection and implementations on the world wide web, could facilitate proforma use with greater overall efficiency for medical and clerical staff.

1 Bull AD, Biffin AHB, Mella J, et al. Colorectal cancer pathology reporting: a regional audit. $\mathcal{f}$ Clin Pathol 997;50:138-42.

2 Shepherd NA, Quirke P. Colorectal cancer reporting: are we failing the patient? F Clin Pathol 1997;50:266-7.

3 Shepherd NA. Pathological prognostic factors in colorectal cancer. In: Kirkham N, Lemoine NR, ed. Progress in pathology, 2nd ed. Edinburgh: Churchill Livingstone, 1995:11541 .

4 Burke HB, Goodman PH, Rosen DB, et al. Artificial neural networks improve the accuracy of cancer survival prediction. Cancer 1996;79:857-62.

5 Bottaci L, Drew PJ, Hartley JE, et al. Artificial neural networks applied to outcome prediction for colorectal cancer patients in separate institutions. Lancet 1997;350:46972 .

6 Oates GD, Finan PJ, Marks CG, et al. Handbook for the clinico-pathological assessment and staging of colorectal cancer, 2nd ed. London: UK Co-ordinating Committee on Cancer
Research, 1997:13

7 Quirke P, Dixon MF, Durdey P, et al. Local recurrence of rectal adenocarcinoma due to inadequate surgical resection. Histopathological study of lateral tumour spread and surgical excision. Lancet 1986;ii:996-9.

8 Cross SS, Bull AD. Is the informational content of histopathological reports increasing? f Clin Pathol 1992;45: 179-80.

9 Appleton MAC, Douglas-Jones AG, Morgan JM. Evidence of effectiveness of clinical audit in improving histopathology reporting standards of mastectomy specimens. F Clin
Pathol 1998;51:30-3. 